\title{
Influence of Korean professional male basketball players' characteristics on preventive health behaviors during COVID-19
}

\author{
Young-Jae $\mathrm{Kim}^{1}{ }^{1}$, Jeong-hyung Cho1, Yeon $\mathrm{Kim}^{2}$,* \\ ${ }^{1}$ Department of Physical Education, Chung-Ang University, 06981 Seoul, Republic of Korea \\ ${ }^{2}$ Department of Sports Kyungil University, 46762 Gyeongsan, Republic of Korea
}

*Correspondence: kimyeon0023@gmail.com (Yeon Kim)

\begin{abstract}
Background and objective: The whole world is suffering extensive damage from COVID-19, and even the world of sports cannot escape this situation. Preventive behavior against COVID-19 is crucial to minimizing this damage. Therefore, this study analyzed data examining preventive behaviors of all Korean professional basketball players, providing empirical evidence of the relationship between preventive health behavior and Big-5 factors depending on socio-demographic variables.

Material and methods: Using an online survey, data were collected from 106 players registered with the Korean Basketball League in the 2019-2020 season.

Results: Married players and those with more years of experience were more thorough in managing injuries and preventing infections. Among the Big-5 personality traits, conscientiousness had a significant effect on COVID-19 prevention and health management behavior. Players low on neuroticism demonstrated higher performance in terms of injury management behavior.

Conclusions: These results provide critical insight regarding the preventive health behavior of professional sports players. The findings can serve as basic data for enhancing COVID-19 preventive behavior of male basketball players, and as a reference for a decrease in damage in professional sports leagues from COVID-19 and normal management and maintenance.
\end{abstract}

\section{Keywords}

COVID-19; Pandemic; Male professional basketball player; Injury; Marriage; Big-5 personality traits; Health prevention behavior

\section{Introduction}

Coronavirus disease 2019 (COVID-19), which originated in Wuhan, China in November 2019, reached Korea in January 2020, and has spread worldwide [1, 2]. As the spread of the infection accelerated, the World Health Organization [3] declared COVID-19 a pandemic-the third such announcement to ever be made. COVID-19 is currently the largest social and environmental disaster in the world, and has significantly impacted national policies and everyday life. The fallout from this pandemic is expected to continue into the foreseeable future [4].
In response to COVID-19, Korea implemented several guidelines, including enforcing social distancing, refraining from group activities, and maintaining strict personal hygiene [2]. These guidelines led to various social changes such as the closure of schools, transition to online classes, mandatory self-isolation of visitors, and closure of churches and other group facilities.

Unsurprisingly, these changes have had a great impact on sports activities globally. The season openings of various sports, including the 2020 Tokyo Olympics, have been postponed $[5,6]$, and the ongoing professional sports seasons have either ended early or continued without spectators. 
In the United States, the National Basketball Association suspended its basketball league after its first COVID-19 case in March 2020 [7], and both the world-renowned English Premier League and Europe's top five professional football leagues were suspended mid-season [8].

This situation has also affected professional players as group training has been discontinued and replaced by individual-led and non-face-to-face training [9]. The social separation of Koreans has been found to play an important role in healthcare behavior given the COVID-19 situation [10]. In addition, Lim [11] reported that Korean professional players prevented injuries through self-management.

Although preventive actions against COVID-19 have been emphasized, it is important to put these actions into practice, since they become meaningless without proper followthorough and individual response [12]. Therefore, it is important to examine preventive actions while considering the characteristics of an individual's personality.

In the case of highly contagious diseases, social characteristics such as preventive behavior are considered important [13]. Additionally, awareness and knowledge relate to the practice guidelines for the prevention of infection [14, 15]. Ahn's 2019 study emphasized that infectious diseases can be prevented if an individual's response is prudent and organized [12].

The study of personality factors, especially to identify health-related behaviors, continues to be important [16]. Studies have shown that openness, extroversion, and neuroticism are particularly related to health behavior [17]. Personality factors are genetically inherited, but can change depending on the individual's psychological and social aspects [18]. Pandemics such as COVID-19 require different coping plans depending on characteristic and personalities of individuals [19], and even mental behavior differs depending neuroticism, morality and ideology [20, 21], because personalities inherent in individuals are expressed in actions in daily life. For instance, roles in sports are assigned for each position, and appropriate characteristics are formed by performing these repetitive tasks. A study has demonstrated differences in the individual characteristics of soccer players depending on the position they played [22], while another study has indicated individual differences based on the position played among handball players [23].

This being said, the positions of players are of more importance in the avenue of professional sports than in amateur leagues or clubs. In particular, the role of each player with regard to their respective position in professional basketball is very important because the players need to move in cooperation with one another on the court. However, these roles vary depending on the individual characteristics of the players (e.g., gender, marital status, injury, years of experience, etc.), and players prepare for the game and these roles even outside of the court [24].

The characteristics of an individual constitute their personality. The consistency, specificity, and totality inherent in their personality can lead to changes in behavior, which can then affect their preventive actions against COVID-19 [25,
26]. Therefore, this study set forth the following hypotheses in order to determine the differences in personalities and health prevention behaviors of Korean professional basketball league players during the COVID-19 pandemic according to their social characteristics:

Hypothesis 1 . Health prevention behavior will vary depending on the age, years of experience, position, and injury experience of the players.

Hypothesis 2. The effects of marital status, injury experience, and years of experience on preventive actions will vary depending on the players' personality.

\section{Materials and methods}

\subsection{Study procedure}

This study was conducted with particular attention not to cause latent, physical, and mental damage to the participants, in compliance with the Helsinki Declaration. Particularly, the questionnaire was organized focusing on not making the participants feel uncomfortable or unpleasant, and this study obeys the ethical norm; harmlessness to participants by formulating the concept of informed consent. This norm is to make the subjects fully understand the risk that this research may bring about and to encourage them to participate voluntarily. Also, one expert in psychiatry, one expert in family medicine, and two experts in social psychology in sports joined to acquire construct validity and content validity of the survey contents. This study adopted an online questionnaire due to the COVID-19 pandemic, and the data were collected under the guarantee of anonymity and secrecy of the participants. The data were collected for a month, and for convenience of players, they were allowed to fill out the questionnaires on mobile phones in their leisure time. The data collected would be processed in accordance with the ' 8 th Principle' Guideline of the OECD Privacy Framework [27].

\subsection{Research participants}

The sample comprised male basketball players registered with the Korean Basketball League. In Korea, men's professional basketball comprises 10 teams, with 140 registered players. This study recruited 113 players, excluding 20 foreign players who found it difficult to participate in online surveys and seven players who could not participate owing to personal reasons. The final dataset comprised the data of 106 players, excluding seven players whose responses had missing values.

Fig. 1 shows the distribution of participant characteristics. To identify the characteristics of the participants, their ages, salary, marital status, years of experience, position, and injury experience were investigated. The average age of the participants was 29.23 years old, with a standard deviation (SD) of 3.92, and the average annual salary ranged from 50 million to 100 million Korean won (KRW) in groups of 31 people $(29.2 \%)$. More than half of the players were unmarried (67.9\%), and the average duration of their professional basketball careers was 15 years, with an SD of 4.53 . The most-held position was the point guard, reported by 33 


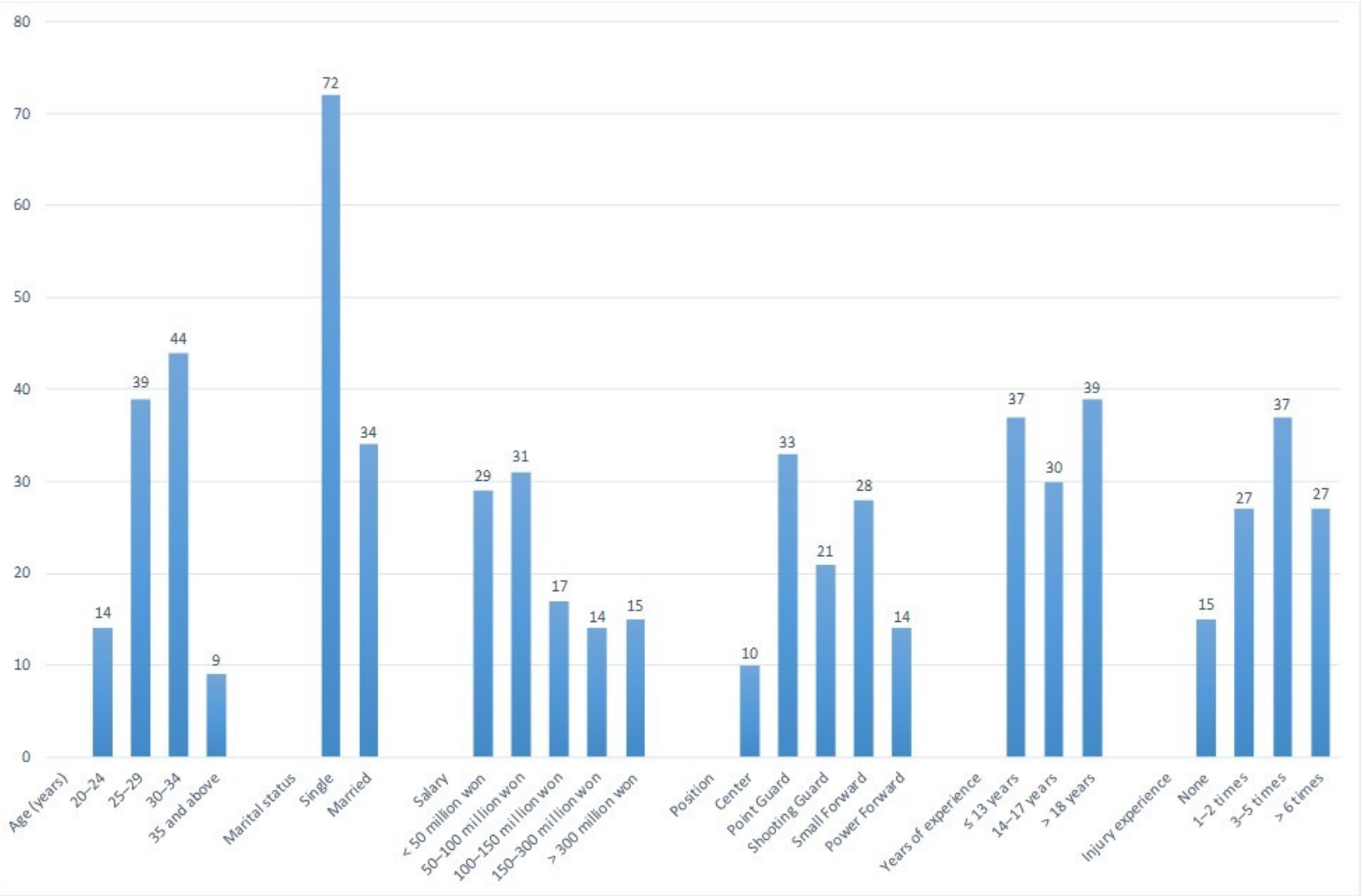

FIG. 1. Participant attribute distribution.

players (31.1\%), and 91 players (85.8\%) reported experiencing injuries.

\subsection{Measurement scales}

The survey consisted of 38 items on the general characteristics of the participants ( 7 items), and the two measurement scales on preventive health behavior for COVID-19 (11 items) and the Big-5 personality traits (20 items).

\subsubsection{COVID-19 preven tive health behavior}

The modified version of a scale originally developed by the Center for Disease Control and Prevention (USA) was used for measuring COVID-19 preventive health behavior. This scale was modified by the Korea Disease Control and Prevention Agency to match the specific conditions of COVID-19 in terms of basic preventive health behavior [10].

The content validity of this survey was verified through advice from a psychiatrist, two doctors in sports sociology, one professional basketball player, and one professional basketball coach. Comprising 11 items, the COVID-19 preventive health behavior scale used a five-point Likert scale. The score ranged from 1 point ("do not agree at all") to 5 points ("strongly agree"), with higher scores indicating a higher level of behavior practiced. The statements included: "I avoid crowded places"; "I avoid meeting people who have fever or respiratory symptoms"; "I cover my mouth and nose with my sleeve when coughing or sneezing"; "I wear a face mask when I have fever or respiratory symptoms, such as a cough"; "I will visit a nearby health care facility if I develop fever or respiratory symptoms (cough, sore throat, etc.) within 14 days of visiting a country or region (Korea) affected by COVID-19"; "I strictly comply with personal hygiene measures, such as not touching my eyes, nose, or mouth with unwashed hands"; "I abstain from smoking and drinking as a precaution against COVID-19"; "I ventilate my room often to maintain fresh air"; "I frequently watch TV programs related to COVID-19"; "I exercise regularly"; and "I maintain good sleeping habits to prevent COVID-19." In a study by Kim and Cho [10], the scale's internal consistency reliability coefficient, Cronbach's $\alpha$, was reported to be 0.84 . In this study, the scale had a Cronbach's $\alpha$ of 0.76 .

\subsubsection{Big-5 personality traits}

The personality measurement tool used in this study was developed by McCrae and Costa [28], who translated the Big Five (brief version) of Turiano et al. [29], which was used in health behavior research.

This scale comprises 20 items, with scores ranging from 1 point ("do not agree at all") to 5 points ("strongly agree"). Each item requires the respondents to indicate the extent to which that item describes them. The five factors evaluated by the scale include agreeableness (I try to behave politely to people, I trust people), conscientiousness (I do hard to achieve my goal, I have a strong sense of responsibility), extroversion (I am lively and full of energy, I like talking with people), neuroticism (I tend to act on impulse, I feel nervous and 
T A B L E 1. Results of exploratory factor analysis on participants' Big-5 personality traits.

\begin{tabular}{|c|c|c|c|c|c|c|}
\hline \multirow{2}{*}{ Sub-factor } & \multirow{2}{*}{ Item } & \multicolumn{5}{|c|}{ Component } \\
\hline & & 1 & 2 & 3 & 4 & 5 \\
\hline \multirow{4}{*}{ Conscientiousness } & Conscientiousness 7 & 0.80 & & & & \\
\hline & Conscientiousness 6 & 0.80 & & & & \\
\hline & Conscientiousness 8 & 0.76 & & & & \\
\hline & Conscientiousness 5 & 0.72 & & & & \\
\hline \multirow{4}{*}{ Openness } & Openness 17 & & 0.85 & & & \\
\hline & Openness 20 & & 0.79 & & & \\
\hline & Openness 18 & & 0.77 & & & \\
\hline & Openness 19 & & 0.76 & & & \\
\hline \multirow{4}{*}{ Extroversion } & Extroversion 10 & & & 0.83 & & \\
\hline & Extroversion 11 & & & 0.80 & & \\
\hline & Extroversion 12 & & & 0.71 & & \\
\hline & Extroversion 9 & & & 0.60 & & \\
\hline \multirow{4}{*}{ Neuroticism } & Neuroticism 15 & & & & 0.86 & \\
\hline & Neuroticism 14 & & & & 0.77 & \\
\hline & Neuroticism 16 & & & & 0.76 & \\
\hline & Neuroticism 13 & & & & 0.67 & \\
\hline \multirow{3}{*}{ Agreeableness } & Agreeableness 2 & & & & & 0.75 \\
\hline & Agreeableness 3 & & & & & 0.72 \\
\hline & Agreeableness 1 & & & & & 0.52 \\
\hline Cronbach's $\alpha$ & & 0.84 & 0.89 & 0.87 & 0.81 & 0.73 \\
\hline Eigenvalue & & 3.54 & 3.16 & 2.77 & 2.57 & 2.12 \\
\hline Variance (\%) & & 17.688 & 15.807 & 13.824 & 12.849 & 10.600 \\
\hline Cumulative (\%) & & 17.688 & 33.495 & 47.319 & 60.168 & 70.769 \\
\hline
\end{tabular}

Bartlett's test of sphericity $=1214.544, d f=190, P<0.001$, KMO Measure of Sampling Adequacy $=0.83$.

restless sometimes), and openness (I like adventures, I am imaginative).

We conducted an exploratory factor analysis to secure the validity and reliability of the personality traits. The results are shown in Table 1. Nineteen items were identified, excluding one item out of 20 (Item No. 4 under the factor of agreeableness), which had a factor loading value of less than 0.5. Further, the Cronbach's $\alpha$ coefficients were calculated for the identified sub-items, and were determined to be as follows: conscientiousness $=0.84$, openness $=0.89$, extroversion $=0.87$, neuroticism $=0.81$, and agreeableness $=0.73$. Thus, the reliability and validity of the personality trait components perceived by male professional basketball players were acceptable.

\subsection{Data analysis}

All analyses in this study were performed after the coding and data cleaning processes. The data were analyzed using SPSS version 25.0. To examine the demographic factors, frequency analysis and descriptive analysis were conducted; exploratory factor analysis and Cronbach's $\alpha$ analysis were used to ensure the validity and reliability of the measurement tools. Lastly, one-way analysis of variance and multiple regression analyses were conducted to analyze the data.

\section{Results}

Table 2 presents an analysis of the differences in the COVID19 preventive behaviors of the participants based on their demographic characteristics. While the most common age group of our participants was 30-34 years (mean $[\mathrm{M}]=4.43$, $\mathrm{SD}=0.50$ ), the group $\geq 35$ years old demonstrated the greatest COVID-19 preventive behaviors $(\mathrm{M}=4.61, \mathrm{SD}=0.32)$. However, this difference was not statistically significant ( $F$ $=0.67, P>0.05)$. In terms of marital status, the married group $(M=4.51, S D=0.39)$ engaged in more COVID-19 preventive behaviors than the single group, with no statistically significant difference between the preventive behaviors of the two groups $(F=1.90, P>0.05)$. In terms of salary, most participants reported a salary range of 50-100 million KRW $(\mathrm{M}=4.33, \mathrm{SD}=0.44)$; however, it was the group reporting a salary range of $100-150$ million $\mathrm{KRW}$ group $(\mathrm{M}=4.62$, $\mathrm{SD}=0.33$ ) that engaged the most in COVID-19 preventive behaviors. There was no significant difference based on years of experience in COVID-19 preventive behaviors among groups $(\mathrm{F}=0.72, P>0.05)$.

Table 3 shows the influence of personality traits on the basketball players' COVID-19 preventive health behavior. Unmarried professional basketball players did a lot of COVID19 preventive behavior when they belonged to conscientiousness $(\beta=0.36, \mathrm{t}=2.68, P<0.01)$ and agreeableness $(\beta=0.28, \mathrm{t}=2.14, P<0.05)$ among diverse personality types. The variance explaining the regression model was $38 \%\left(\mathrm{R}^{2}=0.38\right)$. Married professional basketball players showed a lot of COVID-19 preventive behavior when they only belonged to conscientiousness $(\beta=0.36, \mathrm{t}=2.68, P<$ $0.01)$. The variance explaining the regression model in the group of the married was $41 \%\left(\mathrm{R}^{2}=0.41\right)$. Conscientiousness highly influenced the group with no injury experience, and the variance explaining the regression model was $81 \%\left(\mathrm{R}^{2}=\right.$ 0.81 ), which is very high. On the other hand, neuroticism ( $\beta=-0.53, \mathrm{t}=-2.73, P<0.05)$ negatively influenced the group that had been injured more than six times, occupying the largest proportion of injury frequency among all the groups, and the variance explaining the regression model was $45 \%\left(R^{2}=0.45\right)$. Lastly, in the group with a long career, players with conscientiousness $(\beta=0.48, \mathrm{t}=3.24$, $P<0.05)$ showed a lot of COVID-19 preventive behavior. The variance explaining the regression model was $58 \%\left(\mathrm{R}^{2}=\right.$ 0.58).

Finally, preventive behaviord against diseases such as COVID-19 varied according to personality type. For professional basketball players, the higher their conscientiousness was, the higher their preventive behavior, and the higher their neuroticism was, the lower their preventive behavior. Additionally, the higher their experience of injury, the greater the difference.

\section{Discussion}

This study aimed to provide information on infection prevention and health behavior among professional basketball players by analyzing the relationship between personality 
T A B L E 2. Analysis of differences in preventive health behavior related to COVID-19 based on demographic factors.

\begin{tabular}{|c|c|c|c|c|c|}
\hline Factor & Frequency (\%) & Mean & Standard deviation & $\mathrm{F}$ & Significance probability \\
\hline \multicolumn{6}{|l|}{ Age (years) } \\
\hline $20-24$ & $14(13.2)$ & 4.41 & 0.41 & \multirow{4}{*}{0.67} & \multirow{4}{*}{0.57} \\
\hline $25-29$ & $39(36.8)$ & 4.38 & 0.38 & & \\
\hline $30-34$ & 44 (41.5) & 4.43 & 0.50 & & \\
\hline 35 and above & $9(8.5)$ & 4.61 & 0.32 & & \\
\hline \multicolumn{6}{|l|}{ Marital status } \\
\hline Single & $72(67.9)$ & 4.38 & 0.45 & \multirow[t]{2}{*}{1.90} & \multirow[t]{2}{*}{0.17} \\
\hline Married & $34(32.1)$ & 4.51 & 0.39 & & \\
\hline \multicolumn{6}{|l|}{ Salary } \\
\hline$<50$ million won & $29(27.4)$ & 4.35 & 0.53 & \multirow{5}{*}{1.62} & \multirow{5}{*}{0.18} \\
\hline 50-100 million won & $31(29.2)$ & 4.33 & 0.44 & & \\
\hline $100-150$ million won & $17(16.0)$ & 4.62 & 0.33 & & \\
\hline 150-300 million won & $14(13.2)$ & 4.47 & 0.31 & & \\
\hline >300 million won & $15(14.2)$ & 4.48 & 0.34 & & \\
\hline \multicolumn{6}{|l|}{ Position } \\
\hline Center & $10(9.4)$ & 4.54 & 0.18 & \multirow{5}{*}{2.34} & \multirow{5}{*}{0.06} \\
\hline Point Guard & $33(31.1)$ & 4.45 & 0.34 & & \\
\hline Shooting Guard & $21(19.8)$ & 4.29 & 0.61 & & \\
\hline Small Forward & $28(26.4)$ & 4.55 & 0.36 & & \\
\hline Power Forward & $14(13.2)$ & 4.21 & 0.47 & & \\
\hline \multicolumn{6}{|l|}{ Years of experience } \\
\hline$\leq 13$ years & $37(34.9)$ & 4.43 & 0.38 & \multirow{3}{*}{0.72} & \multirow{3}{*}{0.49} \\
\hline $14-17$ years & $30(28.3)$ & 4.35 & 0.45 & & \\
\hline$>18$ years & $39(36.8)$ & 4.47 & 0.46 & & \\
\hline \multicolumn{6}{|l|}{ Injury experience } \\
\hline None & $15(14.2)$ & 4.37 & 0.52 & \multirow{4}{*}{0.75} & \multirow{4}{*}{0.53} \\
\hline $1-2$ times & $27(25.5)$ & 4.33 & 0.55 & & \\
\hline $3-5$ times & 37 (34.9) & 4.48 & 0.34 & & \\
\hline$>6$ times & $27(25.5)$ & 4.46 & 0.35 & & \\
\hline
\end{tabular}

traits, demographic characteristics, and preventive health behaviors for COVID-19.

Before the COVID-19 pandemic, players have always strived to keep themselves fit to keep the game going. In particular, stretching to prevent injury is related to player quality [30], and control of the post-training diet has been used for the best condition [31]. Moreover, mental stress among the players is relieved through personal leisure activities [32].

Prior to COVID-19, professional athletes needed to focus only on general health management and injury prevention; however, with the onset of the COVID-19 era, professional players have had to increasingly engage in mandatory and highly demanding preventive health behaviors for COVID19 [33]. The degree to which players respond to and participate in this new challenge is expected to play an important role in the future performance of individual players, as well as in the management of professional leagues [34].

Professional basketball players constantly manage themselves, so the older they are and the more experienced they are, the more they manage themselves [10, 14]. Therefore, self-prevention is high to prevent COVID-19 infection. The results of this study showed that older, more experienced, and married athletes showed high preventive behavior, but did not show statistically significant results. These findings are consistent with those of another study [35], wherein the researchers found that married athletes displayed high preventive actions because of having a high sense of responsibility. Given the highly contagious and fast-spreading nature of COVID-19, the infection of a family member or a teammate can result in devastating effects on the other members [13]. As such, it is necessary to adhere to the rules of preventive health behavior not only for oneself, but also for others. Additionally, the further players are in their career, the more likely they are to take on the role of a captain or act as a senior member of the team, while married players are more likely to take charge of their families. Therefore, these players have an increased sense of responsibility, which can translate to a higher likelihood of engaging in preventive health behaviors.

Among the five personality traits, agreeableness and conscientiousness were found to have an important effect on preventive health behavior, while the other three did not have much of an effect. Kindness and sincerity were the lowest in power forwards, depending on position, and the highest in the centers. Basketball players take on various roles depending on their positions, and those playing the center position often take on the role of the team captain. However, experienced or continuously active players also often take on the role of the captain, despite not playing the center position. In other words, the more responsible you are, the more likely you are to perform preventive actions. Therefore, the 
T A B L E 3. Results of regression analysis on COVID-19 preventive health behavior.

\begin{tabular}{|c|c|c|c|c|c|c|c|c|c|c|c|c|}
\hline \multirow{2}{*}{ Factor } & \multirow{2}{*}{$\mathrm{N}$} & \multirow{2}{*}{$\mathrm{R}^{2}$} & \multicolumn{2}{|c|}{ Agreeableness } & \multicolumn{2}{|c|}{ Conscientiousness } & \multicolumn{2}{|c|}{ Extroversion } & \multicolumn{2}{|c|}{ Neuroticism } & \multicolumn{2}{|c|}{ Openness } \\
\hline & & & $\beta$ & $\mathrm{t}$ & $\beta$ & $\mathrm{t}$ & $\beta$ & $\mathrm{t}$ & $\beta$ & $\mathrm{t}$ & $\beta$ & $\mathrm{t}$ \\
\hline Total & 106 & 0.37 & 0.24 & $2.24^{*}$ & 0.41 & $4.10^{* * *}$ & -0.01 & -0.90 & -0.10 & -1.06 & 0.12 & 1.16 \\
\hline \multicolumn{13}{|l|}{ Age (years) } \\
\hline $20-24$ & 14 & 0.21 & -0.12 & -0.36 & 0.46 & 1.32 & 0.00 & 0.00 & -0.09 & -0.28 & -0.27 & -0.68 \\
\hline $25-29$ & 39 & 0.42 & 0.13 & 0.7 & 0.53 & $2.99^{*}$ & -0.15 & -0.76 & -0.15 & -1.00 & 0.29 & 1.72 \\
\hline $30-34$ & 44 & 0.54 & 0.43 & $2.77^{* *}$ & 0.18 & 1.19 & 0.08 & 0.41 & -0.05 & -0.44 & 0.21 & 1.32 \\
\hline 35 and above & 9 & 0.86 & -0.01 & -0.03 & -0.21 & -0.44 & 0.79 & 2.02 & 0.74 & 2.28 & -1.74 & -2.91 \\
\hline \multicolumn{13}{|l|}{ Marital status } \\
\hline Single & 72 & 0.38 & 0.28 & $2.14^{*}$ & 0.36 & $2.68^{* *}$ & -0.03 & -0.23 & -0.15 & -1.40 & 0.19 & 1.52 \\
\hline Married & 34 & 0.41 & 0.16 & 0.87 & 0.5 & $3.04^{* *}$ & 0.21 & 0.92 & 0.19 & 1.16 & -0.16 & -0.76 \\
\hline \multicolumn{13}{|l|}{ Salary } \\
\hline$<50$ million won & 29 & 0.57 & 0.17 & 0.7 & 0.35 & 1.21 & 0.26 & 0.97 & 0.07 & 0.51 & 0.02 & 0.17 \\
\hline 50-100 million won & 31 & 0.32 & 0.32 & 1.58 & 0.25 & 1.16 & 0.08 & 0.38 & -0.07 & -0.37 & 0.02 & 0.09 \\
\hline $100-150$ million won & 17 & 0.33 & 0.23 & 0.63 & 0.56 & 2.08 & -0.48 & -0.8 & -0.13 & -0.39 & 0.42 & 0.66 \\
\hline 150-300 million won & 14 & 0.35 & 0.36 & 0.95 & 0.29 & 0.88 & -0.57 & -1.3 & -0.17 & -0.51 & 0.41 & 1.06 \\
\hline$>300$ million won & 15 & 0.61 & -0.47 & -1.40 & 0.48 & 1.96 & 0.48 & 1.21 & -0.51 & -1.74 & 0.45 & 1.16 \\
\hline \multicolumn{13}{|l|}{ Position } \\
\hline Center & 10 & 0.82 & 0.72 & $3.31^{*}$ & 0.38 & 2.23 & 0.35 & 1.33 & -0.07 & -0.25 & -0.33 & -1.07 \\
\hline Point Guard & 33 & 0.27 & 0.09 & 0.47 & 0.46 & $2.20^{*}$ & 0.00 & -0.05 & 0.13 & 0.72 & -0.12 & -0.61 \\
\hline Shooting Guard & 21 & 0.63 & 0.13 & 0.45 & 0.21 & 0.73 & 0.42 & 1.06 & -0.25 & -1.55 & 0.09 & 0.38 \\
\hline Small Forward & 28 & 0.21 & 0.13 & 0.52 & 0.52 & $2.29^{*}$ & -0.39 & -1.20 & 0.17 & 0.54 & -0.24 & -0.65 \\
\hline Power Forward & 14 & 0.77 & 0.16 & 0.48 & 0.34 & 1.56 & 0.13 & 0.51 & 0.20 & 1.15 & 0.43 & 1.66 \\
\hline \multicolumn{13}{|l|}{ Injury experience } \\
\hline No injuries & 15 & 0.81 & 0.01 & 0.07 & 0.73 & $2.74^{*}$ & -0.11 & -0.48 & 0.01 & 0.07 & 0.30 & 1.18 \\
\hline $1-2$ times & 27 & 0.57 & 0.27 & 1.07 & 0.34 & 1.28 & 0.35 & 0.92 & 0.10 & 0.55 & -0.28 & -1.04 \\
\hline $3-5$ times & 37 & 0.16 & 0.02 & 0.14 & 0.36 & 1.96 & 0.03 & 0.14 & 0.00 & 0.00 & 0.03 & 0.17 \\
\hline$>6$ times & 27 & 0.45 & 0.32 & 1.48 & 0.26 & 1.46 & -0.29 & -1.40 & -0.53 & $-2.73^{*}$ & 0.31 & 1.60 \\
\hline \multicolumn{13}{|l|}{ Years of experience } \\
\hline Less than 13 years & 37 & 0.25 & 0.23 & 1.31 & 0.39 & $2.11^{*}$ & 0.03 & 0.15 & 0.07 & 0.43 & -0.17 & -0.87 \\
\hline $14-17$ years & 30 & 0.36 & 0.31 & 1.41 & 0.2 & 0.85 & -0.01 & -0.08 & -0.2 & -1.09 & 0.38 & 1.78 \\
\hline More than 18 years & 39 & 0.58 & 0.35 & 1.85 & 0.48 & $3.24^{* *}$ & -0.19 & -0.91 & -0.13 & -1.03 & 0.28 & 1.67 \\
\hline
\end{tabular}

$\beta=$ Standardized Coefficients Beta. Note: ${ }^{*}=P<0.05$, $^{* *}=P<0.01$.

most effective way to enforce COVID-19 preventive health behaviors is to instill a sense of responsibility in all players [36]. Regarding this, more attention should be given to power forward players, single players, and less experienced players in order to improve their preventive health behaviors for COVID-19.

Based on these results, neuroticism may be associated with a high degree of avoidance and anxiety regarding infectious diseases [10]. Thus, prevention education should be provided to players with high neuroticism such that they can improve their preventive health behavior and injury management.

This study is significant in that it identified the personality traits and characteristics that affect preventive health behaviors among professional basketball players. However, it has a few limitations. First, although the study is representative of the entire Korean male basketball player population, the findings should be applied to other countries or sports with caution. Second, since this study was conducted against the larger backdrop of the COVID-19 pandemic, caution should be exercised when applying the findings to future preventivehealth studies unrelated to COVID-19. Therefore, a compar- ison of the results of this study with those of studies on other athletes should be carried out to uncover a more complete picture of preventive health behavior in sports athletes. Additionally, international comparisons that specifically address the COVID-19 pandemic should also be explored. Finally, it is necessary to put variables with differences in expected factors as covariates in order to seek verification of specific effectiveness.

\section{Conclusions}

This study supports the need to engage in holistic and widereaching efforts to develop health management programs at the team level. Today, Korea is achieving globally acclaimed, exemplary performance in COVID-19 prevention [37]. To ensure that this performance is also maintained in the field of professional sports, it is necessary for individual athletes, as well as for entire professional teams, to be vigilant and attentive going forward. The major results of this study are as follows. First, it was found that general characteristics of male professional basketball players had partially significant influence on their preventive health behavior. Second, among the five personality types, conscientiousness 
highly influenced COVID-19 preventive behavior and health management behavior. Third, players, who were not neurotic achieved a relatively higher result in injury management behavior.

The findings of this study offer critical implications and guidelines for the preventive health behavior of professional athletes and sports teams, which is essential in the postCOVID-19 era. Furthermore, the results of the study provide important information on the influence of personal and personality characteristics on preventive health behavior. The results of this study can be used as a theoretical and practical reference for the normal operation and maintenance of domestic professional sports leagues.

\section{Author contributions}

Conceptualization, YJK and YK; Methodology, JHC; Validation, YJK, YK and JHC; Formal Analysis, JHC; Investigation, YK and JHC; Data Curation, JHC and YJK; Writing-Original Draft Preparation, YK; Writing-Review and Editing, YK and YJK. All authors have read and agreed to the published version of the manuscript.

\section{Ethics approval and consent to participate}

This study was conducted with particular attention not to cause latent, physical, and mental damage to the participants, in compliance with the Helsinki Declaration. Particularly, the questionnaire was organized focusing on not making the participants feel uncomfortable or unpleasant, and this study obeys the ethical norm.

\section{Acknowledgment}

We would like to express my gratitude to the Korea Professional Basketball Association for your active cooperation in collecting data collection.

\section{Funding}

This research received no external funding.

\section{Conflict of interest}

The authors declare no conflict of interest.

\section{References}

[1] Adegboye OA, Adekunle AI, Gayawan E. Early transmission dynamics of novel coronavirus (COVID-19) in Nigeria. International Journal of Environmental Research and Public Health. 2020; 17: 3054.

[2] Ministry of Health and Welfare. Current status of COVID-19 in Korea. 2020. Available at: http://ncov.mohw.go.kr/bdBoardList_ Real. do (Accessed: 6 April 2020).

[3] World Health Organization. WHO Director-general's opening remarks at the media briefing on COVID-19. 2020. Available at: https://www.who.int/dg/speeches/detail/whodirector-general-s-opening-remarks-at-the-mediabriefing-on-covid-19---11-march-2020 (Accessed: 11 March 2020).
[4] Chae SM. COVID-19 and challenges for future response to infectious diseases. Health Welf. Issue Focus. 2020; 374: 1-8.

[5] Lee YS. Tokyo Olympics postponed. Kyeonggi Ilbo. 2020. Available at: http://www.kyeonggi.com/news/articleView.html? idxno=2260894 (Accessed: 3 March 2020).

[6] Corsini A, Bisciotti GN, Eirale C, Volpi P. Football cannot restart soon during the COVID-19 emergency! A critical perspective from the Italian experience and a call for action. British Journal of Sports Medicine. 2020; 54: 1186-1187.

[7] Kim JH. NBA player with confirmed COVID-19 case... League halts. Korea Times. 2020. Available at: https://newsis.com/view/ ?id=NISX20200313_0000954232 (Accessed: 13 March 2020).

[8] Roan D. COVID-19: The English Premier League to cease temporarily. BBC NEWS/Korea. 2020. Available at: https://www.bbc. com/korean/international-51876933 (Accessed: 14 March 2020).

[9] Lee YH. Year to Tokyo Olympics Taegeuk Warrior training stops with COVID-19. 2020. Available at: https://www.yna.co.kr/view/ AKR20200717123800007 (Accessed: 19 July 2020).

[10] Kim YJ, Cho JH. Correlation between preventive health behaviors and psycho-social health based on the leisure activities of South Koreans in the COVID-19 crisis. International Journal of Environmental Research and Public Health. 2020; 17: 4066.

[11] Lim HG. Good players take good care of their body with less injuries. 2013. Available at: http://mksports.co.kr/view/ 2013/795487/ (Accessed: 2 September 2013).

[12] Ahn BS. Infectious diseases preventable and crisis response possible with individuals and health authorities vigilant. Busan Development Forum. 2019; 8: 38-43.

[13] Ahn MJ. Combating COVID-19: lessons from South Korea. Brookings. 2020. Available at: https://www brookings. edu/blog/techtank/2020/04/13/combating-covid-19lessons-from-south-korea/\#cancel (Accessed: 13 April 2020).

[14] Saiman L, Siegel JD, LiPuma JJ, Brown RF, Bryson EA, Chambers $\mathrm{MJ}$, et al. Infection prevention and control guideline for cystic fibrosis. Infection Control \& Hospital Epidemiology. 2014; 35: 1-67.

[15] Tagg JR, Dierksen KP. Bacterial replacement therapy: adapting 'germ warfare' to infection prevention. Trends in Biotechnology. 2003; 21: 217-223.

[16] Booth-Kewley S, Vickers RR Jr. Associations between major domains of personality and health behavior. Journal of Personality. 1994; 62: 281-298.

[17] Korotkov D. Does personality moderate the relationship between stress and health behavior? Expanding the nomological network of the five-factor model. Journal of Research in Personality. 2008; 42: 14181426.

[18] Loehlin, JC. Resemblance in personality and attitudes between parents and their children. Unequal Chances: Family Background and Economic Success. 2005: 192-207.

[19] Volk AA, Brazil KJ, Franklin-Luther P, Dane AV, Vaillancourt T. The influence of demographics and personality on COVID-19 coping in young adults. Personality and Individual Differences. 2012; 168: 110398.

[20] Qian K, Yahara T. Mentality and behavior in COVID-19 emergency status in Japan: influence of personality, morality and ideology. PLoS ONE. 2020; 15: e0235883.

[21] Modersitzki N, Phan LV, Kuper N, Rauthmann JF. Who is impacted? Personality predicts individual differences in psychological consequences of the COVID-19 pandemic in Germany. Social Psychological and Personality Science. 2020: 1948550620952576.

[22] Di Salvo V, Baron R, Tschan H, Calderon Montero F, Bachl N, Pigozzi F. Performance characteristics according to playing position in elite soccer. International Journal of Sports Medicine. 2007; 28: 222-227.

[23] Srhoj V, Marinović M, Rogulj N. Position specific morphological characteristics of top-level male handball players. Collegium Antropologicum. 2002; 26: 219-227.

[24] te Wierike SCM, Elferink-Gemser MT, Tromp EJY, Vaeyens R, Visscher C. Role of maturity timing in selection procedures and in the 
specialisation of playing positions in youth basketball. Journal of Sports Sciences. 2015; 33: 337-345.

[25] Lee IS. An analysis of Big-5 personality model and business ethics as factors for organizational effectiveness. Journal of Korean Academic Society of Business and Administration. 2003; 32: 1593-1621.

[26] Yun SH. Relationship between 5 personality factors and beauty discipline training of beauty academy consumer. 2020. Unpublished master dissertation, Seokyeong University, Soeoul.

[27] OECD. The OECD privacy framework. 2013. Available at: http://www.oecd.org/sti/ieconomy/oecd_privacy_ framework.pdf (Accessed: 11 July 2013).

[28] Turiano NA, Mroczek DK, Moynihan J, Chapman BP. Big 5 personality traits and interleukin-6: evidence for "healthy Neuroticism" in a US population sample. Brain, Behavior, and Immunity. 2013; 28: 83-89.

[29] McCrae RR, Costa PT. Personality in adulthood: a five-factor theory perspective. New York: Guilford Press. 2003

[30] Amiri-Khorasani M, Sahebozamani M, Tabrizi KG, Yusof AB. Acute effect of different stretching methods on Illinois agility test in soccer players. Journal of Strength and Conditioning Research. 2011; 24: 2698-2704.

[31] Birkenhead KL, Slater G. A review of factors influencing athletes' food choices. Sports Medicine. 2015; 45: 1511-1522.

[32] Hein H, Panhuyzen-Goedkoop N, Corrado D, Hoffmann E, Biffi A,
Delise $\mathrm{P}$, et al. Recommendations for participation in leisure-time physical activity and competitive sports in patients with arrhythmias and potentially arrhythmogenic conditions part I: Supraventricular arrhythmias and pacemakers. European Journal of Cardiovascular Prevention \& Rehabilitation. 2006; 13: 475-484.

[33] Kwon JY. "Coexist with nature"...Survival strategies in the PostCOVID-19 era suggested by Professor Park Ki-soo. 2020. Available at: https://inthenews.co.kr/news/article.html?no= 26762/ (Accessed: 2 September 2020).

[34] Kim NS. Status and challenges of COVID19. Health Welf. Issue Focus. 2020; 373: 1-13

[35] Green CA, Pope CR. Depressive symptoms, health promotion, and health risk behaviors. American Journal of Health Promotion. 2000; 15: 29-34.

[36] Hong JH. [College] Overcoming COVID-19, responsible conscientiousness. 2020. Available at: https://news.unn.net/news/ articleView . html?idxno=227172 (Accessed: 17 March 2020).

[37] Ishaan T. South Korea's coronavirus success story underscores how the U.S. initially failed. 2020. Available at: https: //www . washingtonpost. com/world/2020/03/17/southkoreas-coronavirus-success-story-underscores-howus-initially-failed/ (Accessed: 17 March 2021). 